\title{
Residential Long-Term Care Capacity Planning: The Shortcomings of Ratio-Based Forecasts
}

\author{
Planification de la capacité dans les centres \\ d'hébergement et de soins de longue durée : \\ lacunes des prévisions fondées sur les ratios
}

\author{
(3) \\ YUE ZHANG, PHD \\ Assistant Professor, College of Business and Innovation \\ University of Toledo \\ Toledo, $\mathrm{OH}$
MARTIN L. PUTERMAN, PHD
Professor, Sauder School of Business
University of British Columbia
Vancouver, BC \\ DEREK ATKINS, PHD \\ Professor, Sauder School of Business \\ University of British Columbia \\ Vancouver, BC
}

\begin{abstract}
This paper uses observations from two British Columbia studies to illustrate the shortcomings of widely used ratio-based approaches for residential long-term care capacity planning. It shows that capacity plans based on a fixed ratio of beds per population over age 75 may result in either excess capacity or long wait times for admission. It then investigates the use of linear regression models to obtain a "best" ratio by relating optimal plans derived by rigorous analytical methods to population characteristics and shows that no single ratio applies broadly. While the use of regression is promising, finding these "best" ratios is too analytically complex for general practice. The paper concludes by providing and evaluating an easy-to-use planning
\end{abstract}


method, which we call the average flow model (AFM). The AFM combines demand forecasts with length-of-stay estimates to produce enhanced capacity plans. The AFM is transparent, easily implemented in a spreadsheet and well suited for "what if?" analyses.

\section{Résumé}

Cet article porte sur les observations de deux études britanno-colombiennes afin de dégager les lacunes des démarches de planification de la capacité fondée sur les ratios, grandement utilisées dans les centres d'hébergement et de soins de longue durée. L'article montre que la planification fondée sur un ratio fixe de lits par habitant âgé de plus de 75 ans peut donner lieu soit à un excès de capacité, soit à de longs temps d'attente pour l'admission. L'article examine aussi l'utilisation de modèles de régression linéaire afin d'obtenir le « meilleur » ratio en associant des planifications optimales, dérivées de méthodes analytiques rigoureuses, aux caractéristiques de la population et démontre quaucun ratio unique ne peut s'appliquer à toutes les situations. Bien que l'emploi de la régression soit prometteur, la recherche des « meilleurs » ratios est trop complexe du point de vue analytique. L'article conclut en fournissant et en évaluant une méthode de planification facile à utiliser, que nous nommons le modèle du débit moyen (MDM). Le MDM combine les prévisions de la demande aux estimations des durées de séjour afin de produire une meilleure planification de la capacité. Le MDM est transparent, facile à utiliser dans un tableur et adéquat pour les analyses de simulation.

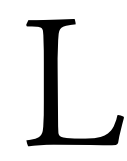
ONG-TERM CARE (LTC) REFERS TO A VARIETY OF MEDICAL AND SUPPORT SERVICES for people with chronic illnesses or disabilities, especially the elderly. LTC services may be provided in the home, through adult day programs, at assisted living facilities or in residential LTC facilities, which are often referred to as "community care facilities" or "nursing homes" (BC Ministry of Health 2011). Throughout this paper, we use the expression "LTC facilities" to refer to residential LTC facilities.

In British Columbia, a professional assessment determines a client's eligibility for LTC services (BC Ministry of Health 2011). When a person's safety becomes a critical issue, independent living is no longer appropriate, or a family caregiver can no longer provide adequate care, residential LTC facilities provide the most appropriate care. Clients admitted to LTC facilities may transfer from hospitals or arrive directly from the community. Most clients remain in a residential facility until they die, while a smaller number may transfer to hospitals or palliative care centres, or return home.

In Canada, the responsibility for LTC is governed by provincial and territorial legislation (Health Canada 2010). In British Columbia, LTC facilities are either operated by regional health authorities or outsourced to private providers on a per diem per capita contract basis. There are also not-for-profit and for-profit privately run facilities. The 2006 Canadian Census shows that seniors aged 65 or over accounted for $13.7 \%$ of Canada's population; this proportion 
will increase more rapidly from 2011, when the first wave of baby boomers born in 1946 reach 65 (Statistics Canada 2009). According to the Canadian Medical Association (2009), an estimated $5 \%$ of Canadians aged 65 and over live in LTC facilities. This aging population and the resulting increased need for LTC presents significant challenges to LTC planners and providers.

Lack of access to residential LTC is often cited as one of the major causes for high volumes of alternative-level-of-care (ALC) patients, who no longer need acute services but occupy acute care beds waiting for discharge to a more appropriate setting. According to the Canadian Institute for Health Information (2009), ALC patients accounted for $14 \%$ of hospital days in acute care hospitals, and 65\% of ALC patients were waiting for admission to a LTC facility. The remainder were waiting for other services, including palliative care, rehabilitation or home care support. These figures suggest that providing sufficient LTC capacity could have a significant impact on acute care wait times, as well as improving patient flow throughout the entire health system.

The methods described here were developed in two studies carried out in British Columbia, Canada: one for a regional health authority and the other for an individual LTC facility. The issues in each case were slightly different, but the underlying question was, "How many residential (LTC) care beds are needed in each of the next 10 to 20 years to ensure that care is provided in a timely fashion?"

Current practice in British Columbia (LABC 2006), Canada (CUPE 2009) and other countries (Wiener et al. 1998; WVHCA 2003; Gibson and Liu 2008) has been to use a fixed ratio of beds per population as the basis for planning. This approach is problematic for several reasons, and has resulted in either long wait times for admission to care or excess capacity (Cohen et al. 2009). In a similar fashion, De Vericourt and Jennings (2011) and Yankovic and Green (2011) considered the efficacy of using fixed patient ratios for nurse staffing, and showed that such policies cannot achieve consistently high and reliable nursing service levels.

There is little published research on capacity planning for LTC services using rigorous methods. As far as we know, the only study addressing this issue was done by Hare et al. (2009), which presented a deterministic system dynamics model for the entire home and community care system, including LTC as an option. Another feature of their model is that it provides forecasts of future demand for services rather than required capacity.

The approach underlying this paper uses operations research and statistical techniques to improve long-term capacity planning for LTC programs and facilities. The technical details are described elsewhere by Zhang et al. (2012). Specifically, a simulation optimization approach was developed to determine the minimum capacity level needed each year to ensure that a specified percentage of clients who are deemed appropriate for admission wait no longer than 30 days to be admitted. We refer to this as the service-based approach. In this paper, we do not describe this service-based approach in depth, but use it as a "gold standard" or benchmark to assess the quality of forecasts obtained through: 
- a universal ratio-based planning guideline,

- an optimized ratio-based method obtained through regression and

- a proposed simpler approach, which we call the average flow model.

\section{The Problem}

This research focuses on LTC capacity planning for either an individual facility or a geographic region in aggregate over a multi-year planning horizon. In order to focus on the main theme of this paper, we have made some simplifications that do not affect our conclusions. In most jurisdictions, including British Columbia, residential LTC facilities are stratified into a number of care paths. The usual ones are complex care, requiring full nursing care; assisted living, for those who can manage most activities of daily living (ADLs), such as dressing and feeding; and occasionally, specialized care facilities such as secure dementia care. Assessment into the right path in most of Canada is based on the internationally used Residential Assessment Instrument for Residential Care (RAI-RC, sometimes referred to as InterRAI-RC). If the designated care provider suspects that home and community care is more appropriate, a similar instrument, the RAI-HC (Residential Assessment Instrument for Home Care), is employed. The Milbank Memorial Fund (2003) provides a comprehensive description of these instruments. Flows between these paths occur but are of an order of magnitude lower than initial entry to LTC, so we ignore them. From now on, we shall refer to a single generic pathway and drop any reference to stratified paths.

The basic flow in our model is from assessment to wait list to admission. As the usage rate is high and wait lists exist, most admissions are triggered by a departure from a LTC facility. Further, we assume that assessment methods and admission requirements remain constant throughout the planning horizon.

We note that in 2003, the BC government announced a new assessment process that restricted access to LTC facilities to those individuals needing "complex care" (Cohen 2003). Those not requiring complex care could remain at home, be assessed for assisted living or seek private residential care. Consequently, from this point on, patients admitted to LTC in British Columbia would be more acute than those admitted prior to 2003. The consequence of this shift is borne out in some of the Vancouver Island data we analyzed in 2009. Figure 1 shows that lengths of stay (LOS) for clients admitted to LTC after 2003 were shorter than those admitted pre-2003, with the pre-2003 median LOS equal to 2.5 years and the post-2003 median LOS equal to 1.8 years. This change had a significant effect on LTC planning. As a result of shorter lengths of stay, fewer beds would be needed to service the same arrival rate.

We also assume that capacity can be changed at the start of any year and by any amount. There might be jurisdictions for which this approach is practical but in the Canadian system, capacity changes mean either "bricks-and-mortar" construction or long-term contractual agreements. It is more likely that capacity change will be "chunky" and likely to be implemented only at a few specified times when physical capacity is added. Hence, our results provide decision- 
makers with capacity targets that can serve as inputs to practical capacity planning decisions. The problem of optimizing practical capacity planning decisions may also take costs and constraints into account (Cohen et al. 1980; Dumas 1985; Ridge et al. 1998; Green 2004), and it might be better approached using more sophisticated operations research techniques, such as multi-period integer or dynamic programming. We do not address this issue further in this paper.

FIGURE 1. Kaplan-Meier estimated LOS distributions for pre-2003 (grey line) and post-2003 (black line) admissions to long-term care on Vancouver Island (circles denote censored data)

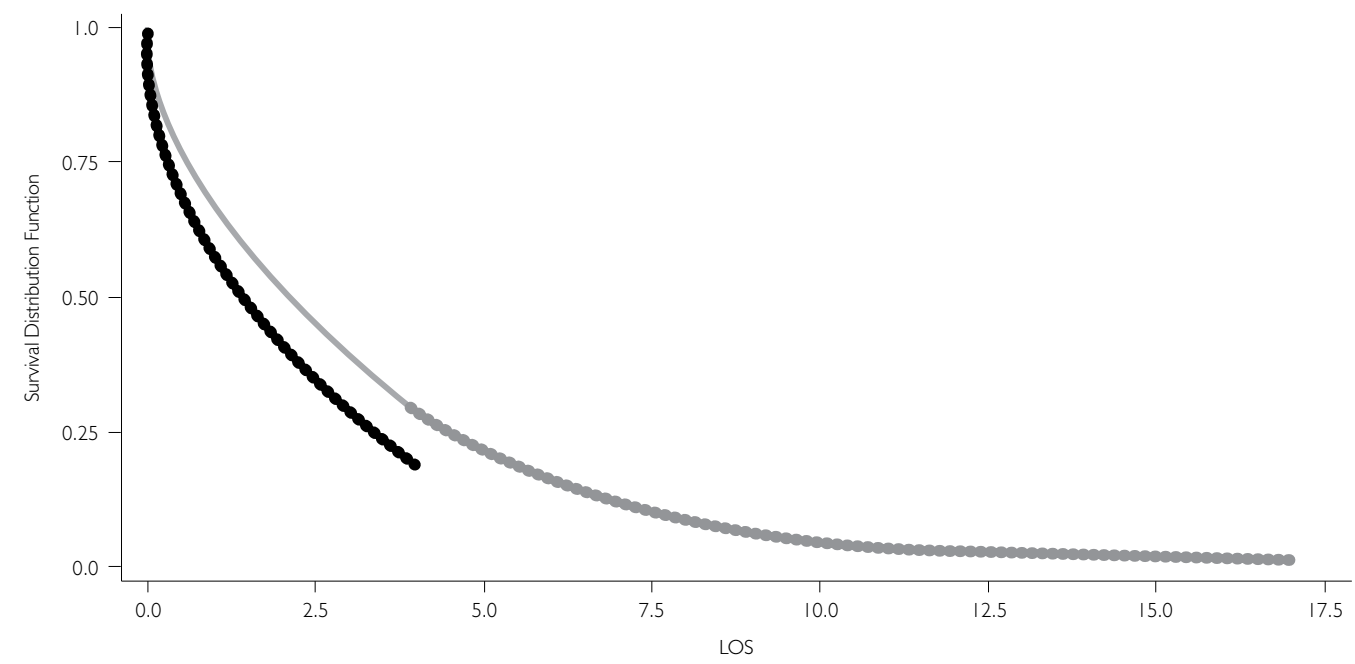

The focus of this paper is how to forecast annual capacity levels (bed requirements) to meet a service-level criterion over a long-term planning horizon. There are a variety of servicelevel criteria used in practice. Focusing on clients' wait time in this research led us to adopt the following service-level criterion: a specified percentage of arriving clients wait no longer than 30 days for admission.

\section{The Service-Based Approach}

There is a long history of using queuing theory (Kleinrock 1975) and computer simulation for capacity planning in the operations research literature. Prior to determining optimal capacity levels, an important issue is to evaluate system performance for specified capacity levels. Queuing theory is usually used to study system performance of simple systems, while complex systems often require simulation. Because queuing theory or simulation by itself cannot find minimum capacity levels required to satisfy a service-level criterion based on system performance, optimization techniques (Nocedal and Wright 2006) may be incorporated to accomplish this.

The LTC system described above may be viewed as a queuing system. However, as pointed out by Zhang et al. (2012), most of the usual analytical assumptions of queuing theory, such as exponential LOS distributions, are violated. That paper developed a discrete event 
simulation (Banks et al. 2005) to model the LTC system over a multi-year planning horizon and integrated optimization techniques into the simulation to find the minimum capacity level required each year to satisfy the service-level criterion. In particular, clients were classified into several groups based on age and gender, each with its own arrival and LOS distributions, which were predicted via demographic and survival analyses (Klein and Moeschberger 2003), respectively. Because that analysis was driven by service levels, we refer to it as the service-based approach. The paper by Zhang et al. (2012) provides all technical details.

\section{Results}

This service-based approach was developed for the Vancouver Island Health Authority (VIHA), where LTC is managed by the Home and Community Care program across 15 geographic regions. We now describe results for one particular region, where there were approximately 2,400 clients in care and 240 clients on the wait list at the time of this study. Data for estimating arrival rates and lengths of stay contained information on past and current clients who arrived between 1995 and 2008. Analysis of these data showed that over $80 \%$ of these clients were over 75 years old when admitted and that arrival and LOS distributions varied by age and gender. Thus, clients were classified into five age groups (below 55, 55-65, 65-75, 75-85 and over 85) and two gender groups, each with its own arrival and LOS distributions. The LOS distribution for each group was modelled by a generalization of an exponential distribution called a Weibull distribution (Marazzi et al. 1998). The method found annual capacity levels over an 11-year planning horizon that ensure that $85 \%$ of clients wait no longer than 30 days for admission.

Capacity forecasts (the number of beds required) during 2009-2020 using the servicebased approach are displayed in Figure 2. In this region, the average service level was $85 \%$ as targeted, and the average time on the wait list was 26 days. We attribute the post-2014 increase in required capacity to the forecasted rapid increase in the 65-85 population in this period. On the other hand, the initial drop in capacity may be due to the following reasons:

- Below-target service levels at the start of the study (VIHA 2009) and long wait lists for admission meant that extra capacity would be needed to achieve the service level in the first year of the planning horizon, 2009.

- The change in admission criteria instituted in British Columbia in 2003, discussed above, might also contribute to this pattern. Because a large number of the pre-2003 admissions who had longer lengths of stay would be leaving the system between 2009 and 2012, less capacity would be needed when they are replaced in the future.

+ $\quad$ BC Stats (2008) forecasted a decline in the population over age 75 during 2009-2013.

\section{Discussion}

Using the capacity plans obtained from the service-based approach as the "gold standard," we investigated whether a ratio policy can produce comparable results. We used the current BC provincial planning ratio of 75 beds per 1,000 population over 75 (LABC 2006) as the 
comparator. Figure 2 is an example in which forecasts based on the ratio method significantly underestimate the capacity requirement in this region for 2009-2018 and may significantly overestimate the capacity requirement after 2020. Furthermore, this ratio produced an inconsistent (varying over time) service level, averaging 3\%, and an average wait list length of over 300. Other regions also demonstrated profound over- or underestimation. This finding suggests that capacity plans based on this ratio value either may not provide adequate service or may create excess capacity.

FIGURE 2. Capacity forecasts obtained using the service-based and ratio-based approaches in a selected region

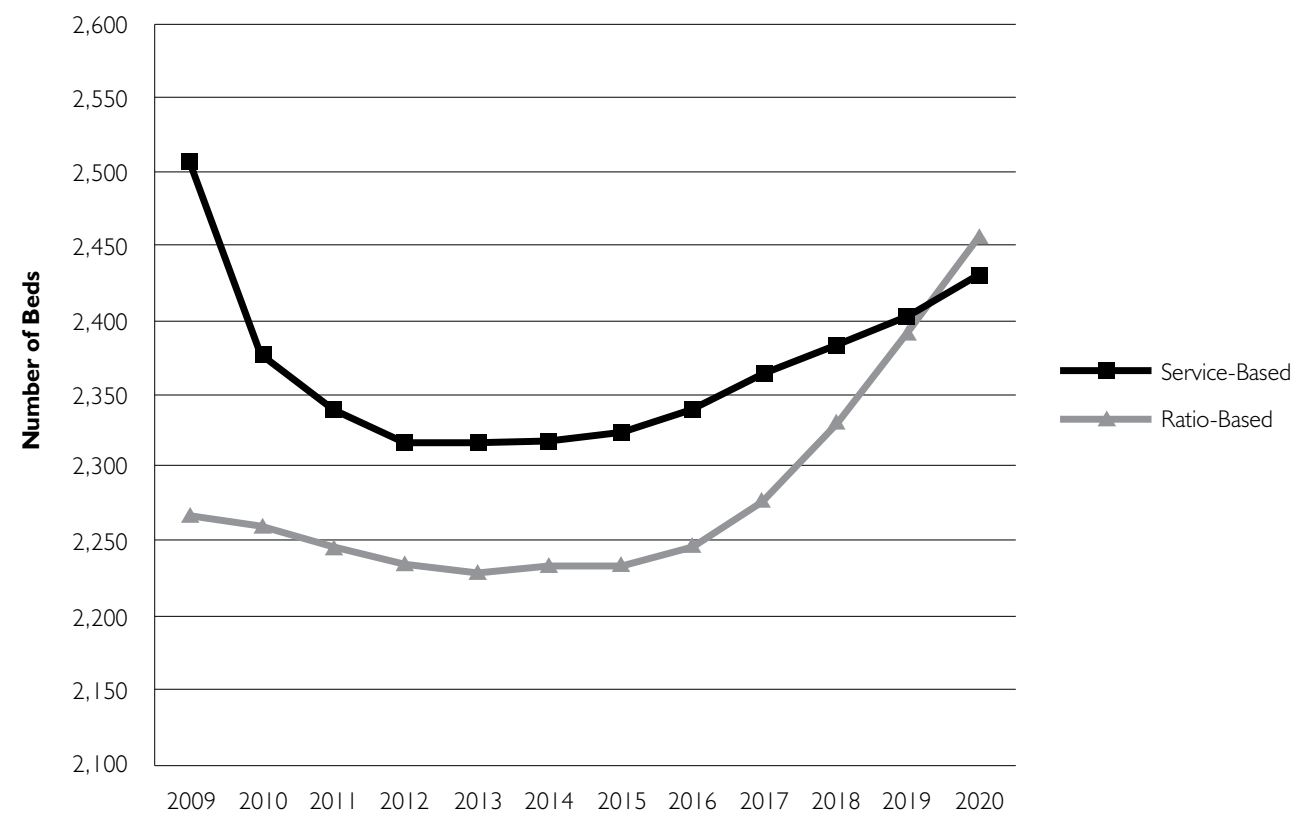

We believe that the shortcomings of the ratio-based approach are that it ignores:

+ the year-to-year dynamics of the system,

- geography-specific differences in arrival and LOS,

- clients in care and on the wait list at the beginning of each year,

- the population below age 75 , who account for $20 \%$ of total clients and

- differences in arrival rates and LOS between the two age groups (75-85 and over 85) and between the two gender groups.

Given the deficiencies of the fixed-ratio method, we posed the question, "Is there a ratiobased policy that can better approximate the service-level forecasts?" To this end, we used statistical methods to find an improved ratio based on the population over 75. A simple linear 
regression model was developed using the capacity forecasts obtained from our service-based approach as the dependent variable, and the population over 75 each year as an explanatory variable. We did not include the data for the first year (2009) in the regression, because it is mainly affected by the current wait list. Also, we set the constant in the regression equal to zero. Based on this regression, the best ratio value was estimated to be 77 beds per 1,000 population over 75 in this region. We refer to this policy as New Ratio A.

FIGURE 3. Capacity forecasts obtained using the service-based approach, New Ratio A and New Ratio $B$ in a selected region

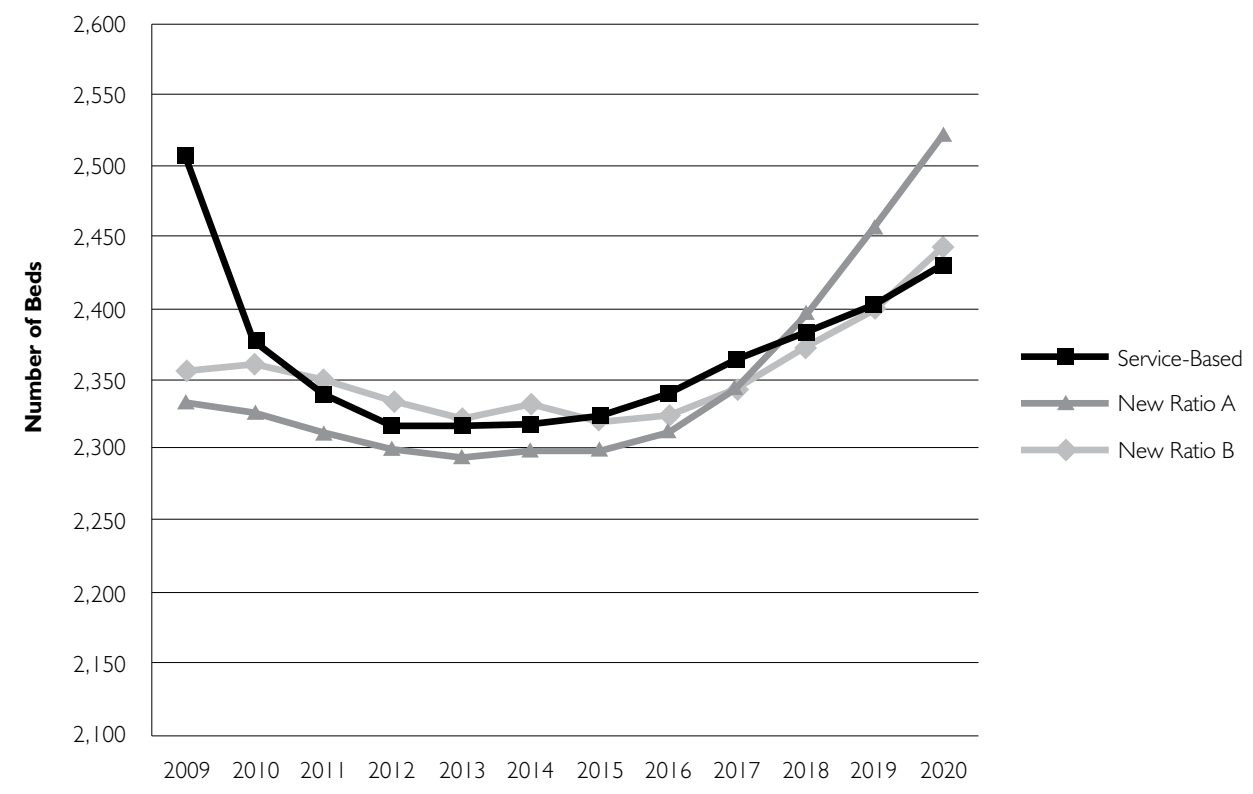

Using the same example, Figure 3 shows that New Ratio A significantly overestimates the capacity levels after 2018. We believe the main reason for this is that subgroups within the population over 75 are not distinguished. The population $75-85$ is growing, while the population over 85 is declining. The size of the population $75-85$ is much larger, but the arrival rate per population for the population $75-85$ is also much smaller than that for the population over 85. In addition, the LOS distributions for these two groups are also different. Hence, any reliable planning method must differentiate between these two population groups (75-85 and over 85). With this in mind, we developed another linear regression model in which the capacity levels achieved by our service-based approach are the dependent variable, and the populations $75-85$ and over 85 are two explanatory variables. Again, the data for the first year was excluded, and the regression constant was set equal to zero. This approach produced the following planning equation for the region under study: 
Number of beds needed $=52$ per 1,000 population $75-85+127$ per 1,000 population over 85 .

We refer to this policy as New Ratio B. Figure 3 shows that New Ratio B more closely approximates the capacity forecasts obtained from the service-based approach. Both the average service level (76\%) and average wait list length (36) based on this policy are closer to those based on the service-based approach than those based on New Ratio A.

However, the two ratio values of this policy were estimated based on a particular geographic region, so a natural question is, "Does this policy produce reliable forecasts in other regions?" That is, can an enhanced, empirically derived ratio policy be applied universally?

To answer this question, we chose another geographic region and compared the capacity forecasts obtained from New Ratio B to those obtained from our service-based approach. Figure 4 shows that New Ratio B does not perform well in this region. This finding suggests that even when taking more information into account, a universally valid ratio policy may not be achievable. Even if a simple ratio policy is needed, it must be customized for each region based on the results obtained from the service-based approach, which negates their value because the more advanced simulation model is required anyway.

The reasons that a universally valid policy may not be achievable include:

- LOS distributions vary between regions, probably because of differences in population characteristics, availability of caregivers and possible variability in assessment criteria.

- Arrival rates per population are different. For example, in rural regions, people may be less willing to live in residential care facilities owing to inconvenient access.

- Population composition varies. For instance, it would be problematic when a ratio policy based only on population over 75 is used in a region where the population aged 55-65 has higher demands for LTC beds.

Because each region has its own demographic characteristics, we do not believe that an accurate universal ratio policy is achievable. Even using other formats or functions in the ratiobased approach may not fundamentally overcome these inherent shortcomings. Therefore, we do not recommend using ratio-based policies for long-term planning.

\section{An Alternative Approach: The Average Flow Model}

The discussion above suggests that planners should not base capacity forecasts on ratios. On the other hand, while our service-based approach is the preferred tool, it takes far too much analytical expertise to implement and maintain on a broad scale. Hence, we propose a simpler method, which we call the average flow model (AFM). The method was developed for our second application. The board of directors of the Louis Brier Home and Hospital in Vancouver, BC, of which one of the authors (M.L. Puterman) was a member, was concerned about expanding its facility's capacity to meet demand for LTC in its target population. What was required was a rigorous but transparent method that could be presented to the board to inform this decision. 
FIGURE 4. Capacity forecasts obtained using the service-based approach and New Ratio B in another region

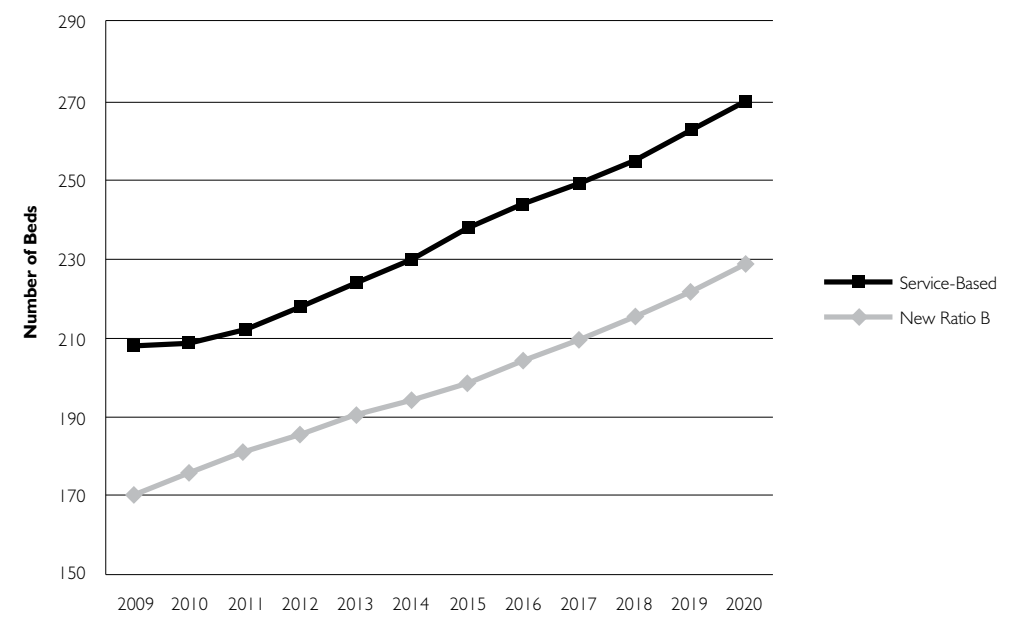

The advantage of the AFM over the rigorous simulation model was its transparency, its ease of implementation in a spreadsheet, the requirement of only annual demand and LOS forecasts as inputs, and its facility in investigating sensitivity of plans to changes in inputs. We show below that this model appears also to provide accurate plans relative to the service-based approach.

The AFM is based on the following two obvious client flow relationships:

Number of beds needed next year $=$ number of beds needed this year - client

$$
\text { departures this year }+ \text { client arrivals this year }
$$

Client departures this year $=$ number of beds this year / average LOS

The first equation is a simple bookkeeping rule; the second equation is derived by assuming that if clients remain in the system for the average LOS, then each year (1/average LOS) clients leave the system. In other words, (1/average LOS) is the departure rate. Therefore, given the estimates of the average LOS and the number of total arrivals in each year, the AFM uses the above two equations to determine the number of beds needed. To put this model in perspective, it can be viewed as a deterministic queuing model and can be programmed easily in a spreadsheet.

Note that this simple model requires estimates of the number of total arrivals in each year and the average LOS as inputs, which can be determined using the same demographic and survival analyses for the service-based approach described by Zhang et al. (2012). Specifically, the number of total arrivals can be calculated by using the historical per capita arrival rate multiplied by a population forecast.

Although the client flow relationships above are described based on the aggregate population, they can be further modified by developing separate models for different client groups stratified by age and gender. In particular, we would recommend considering multiple client 
groups for estimating the number of total arrivals more accurately, which can then be calculated by summing the number of arrivals for each group. Also, for the situations where currently there are many clients on the wait list, the model may even be improved by considering these clients as part of total arrivals in the first year of the planning horizon. On the other hand, the main shortcoming of the AFM is that it ignores the arrival and LOS variability and thus provides no service-level guarantees explicitly. Nevertheless, for planning purposes, one can use the AFM as the basis for sensitivity analysis by changing arrival scenarios and measuring the impact, hence providing insights.

We now offer a simple example of how this approach might be used in practice in a region or at a facility. Suppose average LOS equals 3 years, the current bed capacity is 210 beds and 80 clients are estimated to arrive this year. Then, equation (2) indicates that there will be $210 / 3$ or 70 departures this year. Substituting these three values into equation (1) implies that $210-70+80=220$ beds will be needed in the next year. This process is repeated over the planning horizon to produce a multi-year capacity plan. Through sensitivity analysis, the number of arrivals and LOS can be varied to determine impact on capacity plans.

We found that the AFM performs well in all the geographic regions that we studied. For instance, Figure 5 shows that the capacity forecasts obtained from the AFM have the same pattern as those obtained using the service-based approach in the two regions considered earlier. However, the AFM slightly overestimates the capacity levels. The primary reason is that the second relationship above is based on a system in equilibrium while in LTC systems, LOS and arrival rates vary over time. Empirically, we observed that the number of total departures in each year was slightly greater than that estimated from this relationship. This finding suggests that we might improve forecasts by assuming a slightly shorter LOS.

FIGURE 5. Capacity forecasts obtained using the service-based approach and the AFM in the two regions

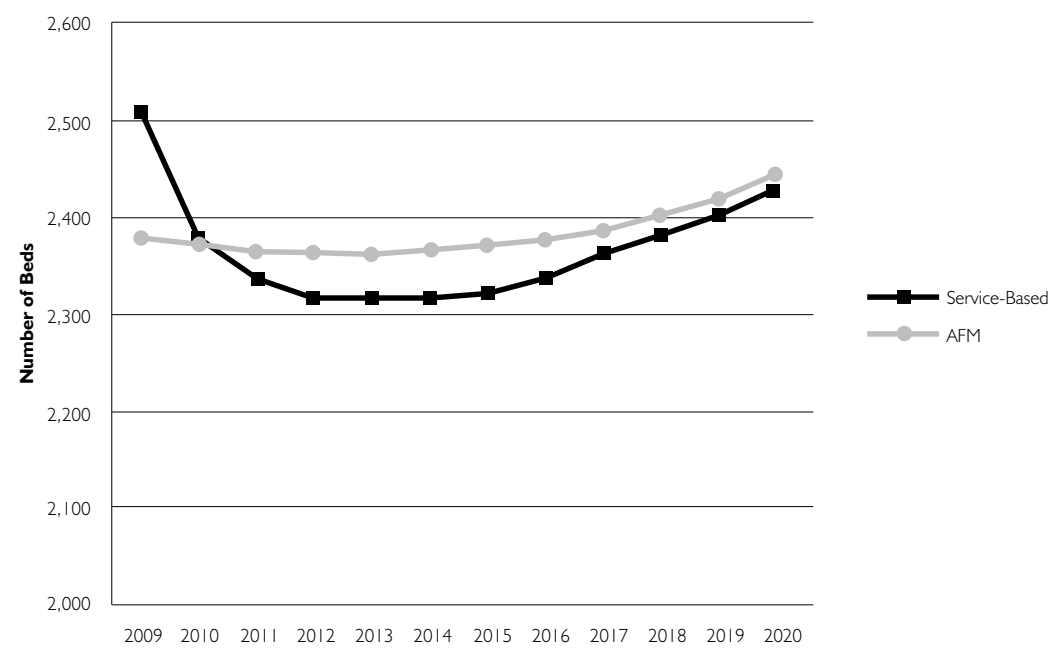


FIGURE 5. Continued

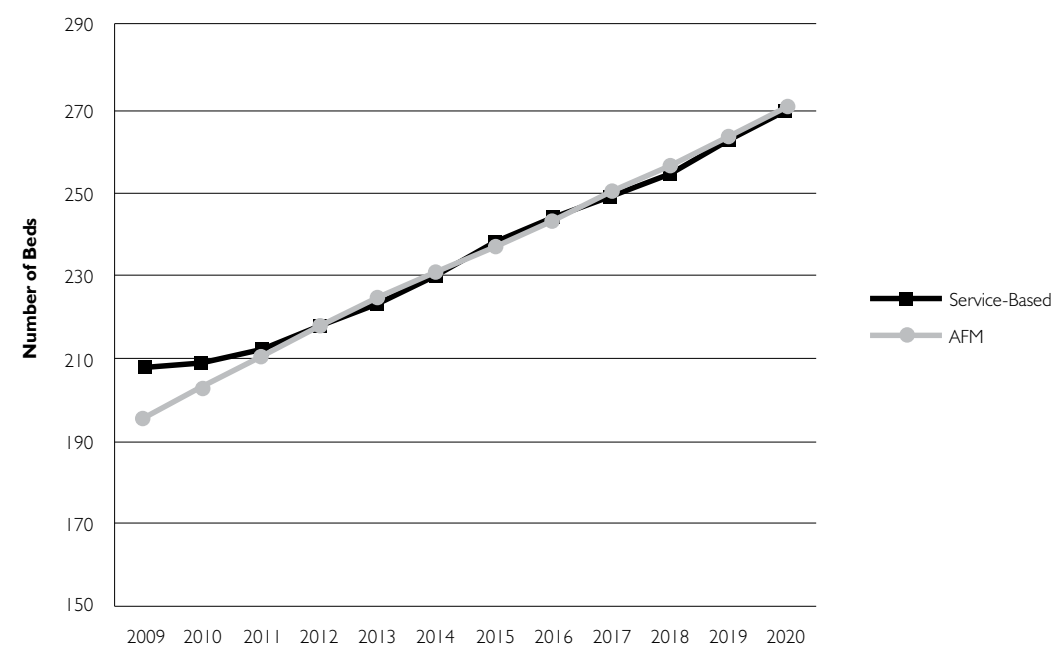

\section{Conclusions}

This paper provides recommendations regarding good approaches for long-term care capacity planning over a multi-year planning horizon. Through case studies using BC data, we compare the service-based approach developed by Zhang et al. (2012) to the widely used ratiobased approach and show the deficiencies of the latter. We then show that empirically derived ratio methods do not improve results sufficiently and propose the AFM as an easy-to-use and intuitive alternative. Table 1 describes the inputs needed, analytic tools required and our brief comments regarding the different approaches discussed in this paper. The ratio-based approach needs only population forecasts from the Census data; the service-based approach and the AFM require similar data, but the latter uses the data in a simpler way.

TABLE 1. Data required by the ratio-based approach, the service-based approach and the AFM

\begin{tabular}{|l|l|l|l|}
\hline Method & $\begin{array}{l}\text { Inputs } \\
\text { (Items below are needed on an } \\
\text { annual basis over the planning } \\
\text { horizon) }\end{array}$ & $\begin{array}{l}\text { Analytic Tools } \\
\text { Required }\end{array}$ & Comments \\
\hline Current Ratio & Forecast of population over 75 & Multiplication & Easy to use but unreliable. \\
\hline New Ratio A & Forecast of population over 75 & Simple regression & $\begin{array}{l}\text { Requires output of service-based model for } \\
\text { calibration - not transportable between regions. }\end{array}$ \\
\hline New Ratio B & $\begin{array}{l}\text { Forecast of population between } \\
75 \text { and } 85 \text { and over 85 }\end{array}$ & Multiple regression & $\begin{array}{l}\text { Requires output of service-based model for } \\
\text { calibration - not transportable between regions. }\end{array}$ \\
\hline Average Flow & $\begin{array}{l}\text { Forecast of total demand and } \\
\text { average LOS }\end{array}$ & $\begin{array}{l}\text { Survival analysis to estimate } \\
\text { average LOS }\end{array}$ & $\begin{array}{l}\text { Easy to use, somewhat reliable and transparent } \\
\text { to users. Facilitates sensitivity analysis. }\end{array}$ \\
\hline $\begin{array}{l}\text { Service-Based } \\
\text { Model }\end{array}$ & $\begin{array}{l}\text { Stratified forecasts of total } \\
\text { demand and historical LOS } \\
\text { distributions }\end{array}$ & $\begin{array}{l}\text { Parametric survival analysis, } \\
\text { simulation, optimization }\end{array}$ & $\begin{array}{l}\text { The "gold-standard." Highly flexible but } \\
\text { challenging to apply. Requires operations } \\
\text { research expertise. }\end{array}$ \\
\hline
\end{tabular}


Our key finding is that ratio-based planning methods often result in either excess capacity or low service levels, and we recommend that they not be used for long-term planning. Because our service-based approach is driven by service levels, it is preferable to commonly used ratio-based approaches.

Although it is not realistic to expect each community or health region to develop and implement the service-based approach, we believe that any provincial ministry in Canada has the capabilities to conduct this analysis. One feasible long-term solution could be that a provincial ministry conducts this analysis once every five years and provides the relevant information to constituent communities or health regions so that they can use it to construct "New Ratio B"-type local solutions. Alternatively, when there are insufficient resources or capabilities to develop and implement the service-based approach, the proposed AFM provides an easyto-use and reliable tool.

As noted above, the AFM was developed and used for LTC planning at the Louis Brier Home and Hospital. Results were well received by the board of directors, which supported the decision to expand capacity on-site. Planning for this expansion is now underway.

Our work is the first attempt to develop a rigorous but practical approach that can be used by managers of LTC programs or facilities to evaluate system performance and for longterm capacity planning. We are hopeful that using this approach will result in both improved access to LTC and reduced ALC patients in acute care. This research no doubt has applications to other health system capacity decisions that currently use fixed-ratio methods.

\section{ACKNOWLEDGEMENTS}

We gratefully thank Steve Atkinson, Director of Operations Research, Vancouver Island Health Authority, and Peter Kafka, Chief Executive Officer of the Louis Brier Home and Hospital, for providing data and many helpful discussions.

Correspondence may be directed to: Yue Zhang, Assistant Professor, College of Business and Innovation, University of Toledo, 2801 W. Bancroft St., Toledo, OH, USA 43606; e-mail: yue. zhang@utoledo.edu.

\section{REFERENCES}

Banks, J., J. Carson, B. Nelson and D. Nicol. 2005. Discrete-Event System Simulation (4th ed.). Upper Saddle River, NJ: Prentice Hall.

BC Ministry of Health. 2011. Home and Community Care Policy Manual: A Guide to Your Care. Retrieved February 24, 2012. <http://www.health.gov.bc.ca/library/publications/\#h>.

BC Stats. 2008. “British Columbia Population Projection - PEOPLE 32." Retrieved February 24, 2012. <http:// www.bcstats.gov.bc.ca>.

Canadian Institute for Health Information. 2009. Alternate Level of Care in Canada. Retrieved February 24, 2012. $<$ http://secure.cihi.ca/cihiweb/products/ALC_AIB_FINAL.pdf>.

Canadian Medical Association. 2009 (August). “Toward a Blueprint for Health Care Transformation.” Discussion paper prepared for the 143rd meeting of the CMA General Council. Ottawa: Author. 
Canadian Union of Public Employees (CUPE). 2009. Residential Long-Term Care in Canada: Our Vision for Better Seniors' Care. Retrieved February 24, 2012. <http://www.cupe.ca/updir/CUPE-long-term-care-seniors-care-vision.pdf>.

Cohen, M. 2003. “A Dramatic Reversal of Policy on Long-Term Care." Retrieved February 24, 2012. <http://www. policyalternatives.ca/sites/default/files/uploads/publications/BC_Office_Pubs/health_restructuring.pdf $>$.

Cohen, M.A., J.C. Hershey and E.N. Weiss. 1980. “Analysis of Capacity Decisions for Progressive Patient Care Hospital Facilities." Health Services Research 15: 145-60.

Cohen, M., T. Jeremy and J. Baumbusch. 2009. “An Uncertain Future for Seniors: BC's Restructuring of Home and Community Health Care, 2001-2008." Retrieved February 24, 2012. <http://www.policyalternatives.ca/taxonomy/term/58/all?page $=1>$.

De Vericourt, F. and O. Jennings. 2011. "Nurse Staffing in Medical Units: A Queueing Perspective”. Operations Research 59: 1320-31.

Dumas, M.B. 1985. “Hospital Bed Utilization: An Implemented Simulation Approach to Adjusting and Maintaining Appropriate Levels." Health Services Research 20: 42-61.

Gibson, D. and Z. Liu. 2008. "Planning Ratios and Population Growth: Will There Be a Shortfall in Residential Aged Care by 2021?" Australasian Journal on Ageing 14(2): 57-62.

Green, L.V. 2004. “Capacity Planning and Management in Hospitals." In M.L. Brandeau, F. Sainfort and W.P. Ierskalla, eds., Operations Research and Health Care: A Handbook of Methods and Applications. London: Kluwer.

Hare, W.L., A. Alimadad, H. Dodd, R. Ferguson and A. Rutherford. 2009. “A Deterministic Model of Home and Community Care Client Counts in British Columbia." Health Care Management Science 12(1): 80-98.

Health Canada. 2010. Long-Term Facilities-Based Care. Retrieved February 24, 2012. <http://www.hc-sc.gc.ca/hcssss/home-domicile/longdur/index-eng.php>.

Klein, J.P. and M.L. Moeschberger. 2003. Survival Analysis: Technique for Censored and Truncated Data (2nd ed.). New York: Springer-Verlag.

Kleinrock, L. 1975. Queue System I: Theory. New York: Wiley.

Legislative Assembly of British Columbia (LABC). 2006. Creating Patient Flow. Retrieved February 24, 2012. $<$ http://www.llbc.leg.bc.ca/Public/PubDocs/bcdocs/401348/Creating_Patient_Flow.pdf > .

Marazzi, A., F. Paccaud, C. Riffieux and C. Beguin. 1998. “Fitting the Distributions of Length of Stay by Parametric Models." Medical Care 36(6): 915-27.

Milbank Memorial Fund. 2003. Implementing the Resident Assessment Instrument: Case Studies of Policymaking for Long-Term Care in Eight Countries. Retrieved February 24, 2012. <http://www.milbank.org/reports/ interRAI/030222interRAI.html>.

Nocedal, J. and S.J. Wright. 2006. Numerical Optimization. New York: Springer-Verlag.

Ridge, J.C., S.K. Jones, M.S. Nielsen and A.K. Shahani. 1998. “Capacity Planning for Intensive Care Units.” European Journal of Operational Research 105: 346-55.

Statistics Canada. 2009. "Age and Sex." Retrieved February 24, 2012. <http://www12.statcan.ca/census-recensement/2006/rt-td/as-eng.cfm>.

Vancouver Island Health Authority (VIHA). 2009. “Backgrounder: VIHA Statistics.” Retrieved February 24, 2012. <http://www.viha.ca/NR/rdonlyres/27D1F70A-DDB4-4887-AA24-20AF6798DA6D/0/year_end_ stats_bg_may09.pdf>.

West Virginia Health Care Authority (WVHCA). 2003 Long Term Care Task Force. Retrieved February 24, 2012. $<$ http://www.hcawv.org/PolicyPlan/wr16.htm>.

Wiener, J.M., D.G. Stevenson and S.M. Goldenson. 1998. Controlling the Supply of Long-Term Care Providers at the State Level. Occasional Paper Number 22. Washington, DC: Urban Institute. Retrieved February 24, 2012. <http://www.urban.org/publications/308047.html>.

Yankovic, N. and L.V. Green. 2011. “Identifying Good Nursing Levels: A Queuing Approach”. Operations Research 59: 942-55.

Zhang, Y., M.L. Puterman, M. Nelson and D. Atkins. 2012."A Simulation Optimization Approach to Long-Term Care Capacity Planning." Operations Research 60(2): 1-13. 